\title{
Determinação de características mecânicas de folhas de papel utilizando a técnica de tomografia por coerência óptica, e suas aplicações na área forense
}

Determination of mechanical characteristics of sheets of paper using the optical coherence tomography technique and its applications in forensic sciences

\author{
Lucas A. S. Ribeiro ${ }^{1 @}$, O. Negrini Neto ${ }^{1}$, Anderson Zanardi de Freitas ${ }^{* 1}$ \\ ${ }^{1}$ Instituto de Pesquisas Energéticas e Nucleares, São Paulo, SP, Brasil.
}

Recebido em 09 de novembro de 2021. Revisado em 03 de janeiro de 2022. Aceito em 24 de janeiro de 2022.

\begin{abstract}
Apresentamos nesse trabalho, uma metodologia para avaliar a pressão de punho durante o processo de escrita manual. Utilizando a tomografia por coerência óptica, foi possível determinar a deformação sofrida pelo papel durante o processo de escrita manual. Foi realizada uma calibração da deformação sofrida pelo papel em função da pressão exercida pela caneta, tornando possível determinar vários parâmetros de interesse, como por exemplo, o raio da esfera da ponta da caneta $R=488 \pm 2 \mu \mathrm{m}$, o coeficiente de Poisson $\nu=0,30 \pm 0,02$ e o módulo de Young efetivo do papel sulfite $75 \mathrm{~g} / \mathrm{m}^{2}$.

Para tal, desenvolvemos um método de determinação do módulo de Hooke para uma mola, com a qual construímos um dispositivo para aplicação de uma força conhecida a uma caneta esferográfica durante o processo de escrita manual.

Realizamos também o estudo em função do tipo de substrato, sendo que cinco voluntários tentaram copiar a mesma assinatura em quatro tipos diferentes de papel. Com o auxílio da técnica de tomografia por coerência óptica demonstramos que é possível diferenciar a autoria de uma assinatura também pela profundidade da deformação no papel. O procedimento experimental tornou possível ainda determinar o coeficiente de Poisson e determinar o Módulo de Young efetivo do papel.
\end{abstract}

Palavras-chave: Tomografia por coerência óptica, módulo de Young, coeficiente de Poisson, deformação mecânica, medidas forenses.

In this work, we present a methodology to assess wrist pressure during the handwriting process. Using optical coherence tomography, it was possible to determine the deformation suffered by the paper during the handwriting process. A calibration of the deformation suffered by the paper as a function of the pressure exerted by the pen was performed, making it possible to determine several parameters of interest, such as the radius of the pen tip sphere $\mathrm{R}=488 \pm 2 \mu \mathrm{m}$, the Poisson coefficient $\nu=0.30 \pm 0.02$ and the effective Young's modulus of bond paper $75 \mathrm{~g} / \mathrm{m}^{2}$.

To this end, we developed a method for determining the Hooke modulus for a spring, with which we built a device for applying a known force to a ballpoint pen during the handwriting process.

We also performed the study depending on the type of substrate, with five volunteers trying to copy the same signature on four different types of paper. Using the optical coherence tomography technique, we demonstrate that it is possible to differentiate the authorship of a signature also by the depth of deformation on the paper. The experimental procedure also made it possible to determine the Poisson's coefficient and determine the effective Young's Modulus of the paper.

Keywords: Optical coherence tomography, Young's modulus, Poisson's coefficient, mechanical strain, forensic measurements.

\section{Introdução}

As tensões e deflexões decorrentes do contato entre dois sólidos elásticos têm aplicação prática em testes de dureza, desgaste, danos por impacto, projeto de próteses dentárias, engrenagens, rolamentos de esferas e rolos, entre outros, sendo essas a base da mecânica dos sólidos.

\footnotetext{
*Endereço de correspondência: freitas.az.ipen@gmail.com
}

Em muitos casos, o contato entre um "penetrador" rígido e uma "amostra" plana e extensa é de particular interesse. As concentrações de tensão e deformação são geralmente mais críticas nos pontos de contato [1]. Neste trabalho apresentamos uma nova metodologia para a medida da pressão exercida pelo punho de um escritor no ato de escrever. Em particular, estudamos assinaturas. Ao escrever um texto, cada pessoa exerce uma pressão de punho diferente que depende de processos neurológicos 
e psicomotores [2, 3. Ao realizar uma escrita, a pressão exercida pela caneta ao substrato - neste caso, o papel -, sofre uma deformação. Essa deformação foi medida com uma técnica interferométrica conhecida como tomografia por coerência óptica - OCT (do inglês Optical Coherence Tomography).

A técnica do OCT, utilizada nestes experimentos, é baseada no interferômetro de Michelson, que utiliza como fonte luminosa um LED superluminescente ou seja, de grande largura de banda (vários comprimentos de onda em fase), que fazendo uso do comprimento de coerência da luz possibilita a medida de estruturas micrométricas de superfícies ou meios espalhadores [4, 5]. A técnica utiliza luz na região do infravermelho do espectro eletromagnético para produzir imagens tomográficas a partir de um meio espalhador. Fornece imagens seccionais de estruturas, em alta resolução, de forma não invasiva, utilizando radiação não ionizante e em tempo real [6, 7]. Informações do material como coeficiente de espalhamento óptico, propriedade birrefringente e outras são coletadas em função da amostra profundidade (AScan) e são usados para construir uma imagem transversal (B-Scan) em tempo real. Análogo ao ultrassom, o OCT mede a intensidade de retroespalhamento da luz infravermelha em vez do som, registrando essa intensidade em função da profundidade. Uma das grandes vantagens dessa técnica é que as amostras não precisam de nenhum preparo prévio, o que evita qualquer alteração devido a esse procedimento. Além disso, as imagens seccionais podem ser utilizadas para reconstruir uma representação da estrutura tridimensional das amostras.

As deformações medidas pelas imagens de OCT carregam informações da distribuição da pressão exercida pelo escritor. Para a calibração da pressão exercida, foi desenvolvido um dispositivo para aplicar diferentes forças conhecidas, em traçado de linhas paralelas num papel sulfite. Para o desenvolvimento desse dispositivo foi necessária a determinação da constante $\mathrm{k}$ de uma mola e o desenvolvimento de um suporte para uma caneta esferográfica.

Para medir o raio da esfera da caneta esferográfica, foi desenvolvido um algoritmo a partir das imagens obtidas por meio da OCT, sendo obtidas as medidas da esfera da caneta esferográfica pela utilização do algoritmo desenvolvido e pelo software ImageJ [8].

Embora não tenha sido o objetivo básico deste trabalho, a metodologia desenvolvida possibilitou ainda a avaliação de alguns parâmetros do próprio papel suporte, como o módulo de Young e o Coeficiente de Poisson. Com relação ao papel, esses parâmetros são de difícil medição e a literatura é escassa, existindo técnicas diferentes que apresentam resultados muito distintos 9. Apresentamos alguns resultados obtidos nas medidas destes parâmetros movidos mais por um objetivo didático, visando introduzir esses importantes conceitos estudados na mecânica do contato.
O trabalho está assim organizado: na Seção 2 Materiais e métodos, são apresentados o dispositivo desenvolvido para a calibração da força exercida sobre o papel. Consideramos apenas a força normal ao papel e as deformações apenas nesta direção, desconsiderando as tensões no plano, ou seja, consideramos que o coeficiente de Poisson do plano é nulo ${ }^{1}$ na Seção 3 - Discussão, apresentamos os resultados das medidas efetuadas e as possíveis aplicações da metodologia na área forense. A Seção 4-Conclusão destina-se às conclusões sobre os resultados e levanta-se a questão sobre a avaliação do módulo de Young e do coeficiente de Poisson e são apontados caminhos para futuros desenvolvimentos e aplicações da metodologia desenvolvida. Na última Seção, 5 - As referências consultadas.

\section{Materiais e Métodos}

\subsection{Desenvolvimento e utilização do dispositivo para aplicação de força}

Para o desenvolvimento do dispositivo utilizado para aplicação força conhecida da caneta sobre o papel, foi realizada a calibração de uma mola para a determinação da sua constante k. A determinação da constante $\mathrm{k}$ da mola foi baseada na medida do deslocamento da mola em função de uma força aplicada conhecida. Para isso utilizamos uma régua de alumínio de $30 \mathrm{~cm}$, com incerteza de $0,05 \mathrm{~cm}$, que foi fixada à vertical. A mola foi fixada à parte superior desse apoio, de forma que ela fosse deformada apenas verticalmente. Na extremidade livre da mola foi colocada uma base para objetos pequenos, com este sempre em contato com a régua, para que pudesse ser marcada a deformação da mola. Na Figura 1 encontra-se uma foto do aparato desenvolvido.

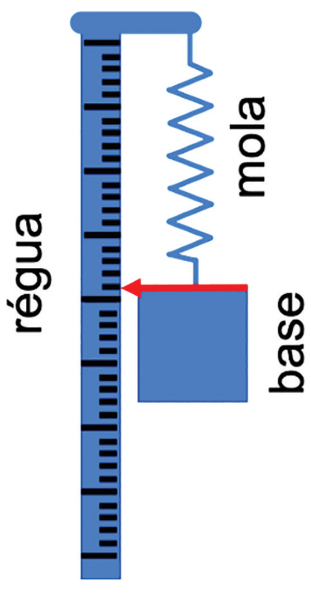

(a)

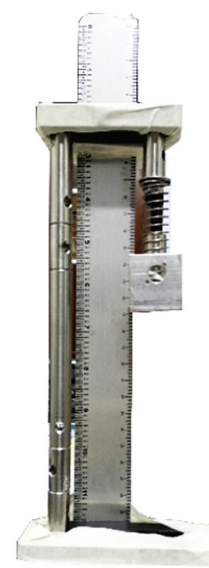

(b)

Figura 1: (a) Diagrama do experimento para medida da constante $\mathrm{k}$ da mola. Em (b) foto do aparato experimental desenvolvido.

\footnotetext{
1 O coeficiente de Poisson representa a razão entre a deformação transversal ao plano e a normal a este plano causadas pela força.
} 


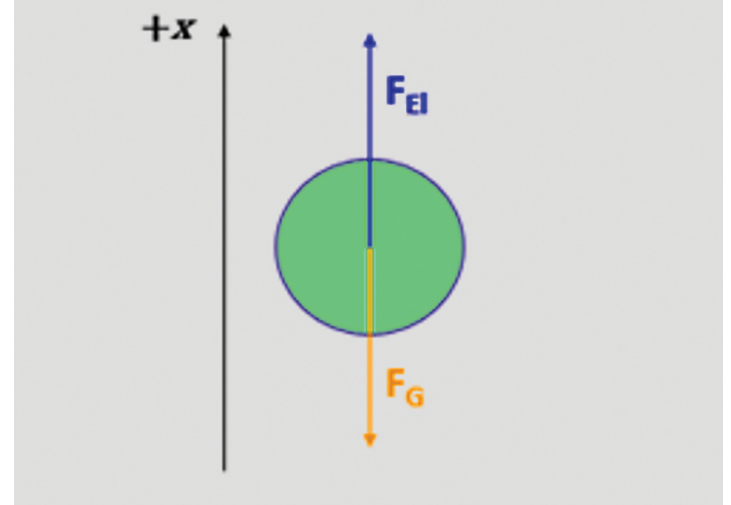

Figura 2: Representação vetorial das forças atuantes no conjunto base e objeto.

Após a montagem do dispositivo, foram medidas as massas de diferentes objetos com tamanhos adequados à base do aparelho. Para isso, foi utilizada a balança analítica EEQ9003 - Edutec®, de precisão 0,0001 g. Os valores de massa variaram de $97,4012 \mathrm{~g}$ a $377,2266 \mathrm{~g}$. Para cada objeto, foram anotados os valores de massa e as posições na régua na condição de equilíbrio entre a força gravitacional e a força exercida pela mola.

Uma vez que o conjunto mola e base esteja em equilíbrio, quando não há um objeto extra, pode-se considerar a posição da régua em que a base se encontra como posição inicial. Ao colocar um objeto sobre ela, é possível analisar o conjunto como um sistema tipo massa-mola, na qual a massa está sujeita a duas forças verticais de sentidos opostos, a gravitacional e a elástica. Sendo $\boldsymbol{x}$ o vetor direcional vertical, com sentido para cima, é possível representar vetorialmente as forças mencionadas (Figura 2):

A força gravitacional, que é devido à interação entre a massa e a Terra, tem direção para baixo, e é descrita pela equação (1):

$$
\boldsymbol{F}_{\boldsymbol{G}}=-m g \widehat{\boldsymbol{x}}
$$

onde $m$ é a massa do objeto acoplado à mola; $g$ é a aceleração gravitacional da Terra e $\widehat{\boldsymbol{x}}$ o versor do eixo. A força elástica, por sua vez, é descrita pela lei de Hooke, e representa a interação entre a mola e a massa:

$$
\boldsymbol{F}_{\boldsymbol{E} \boldsymbol{l}}=k \Delta x \widehat{\boldsymbol{x}}
$$

com $k$ sendo a constante elástica da mola e $\Delta x$ a elongação, ou seja, o quanto a mola foi comprimida ou esticada em relação à posição de equilíbrio. Quando o conjunto entra novamente em equilíbrio, as forças atuantes passam a ter a mesma intensidade, permitindo combinar as formas escalares das equações (1) e (2):

$$
m g=k \Delta x
$$

Uma vez que os valores de $m$ foram obtidos por meio da balança de precisão, e $\Delta x$ através do deslocamento

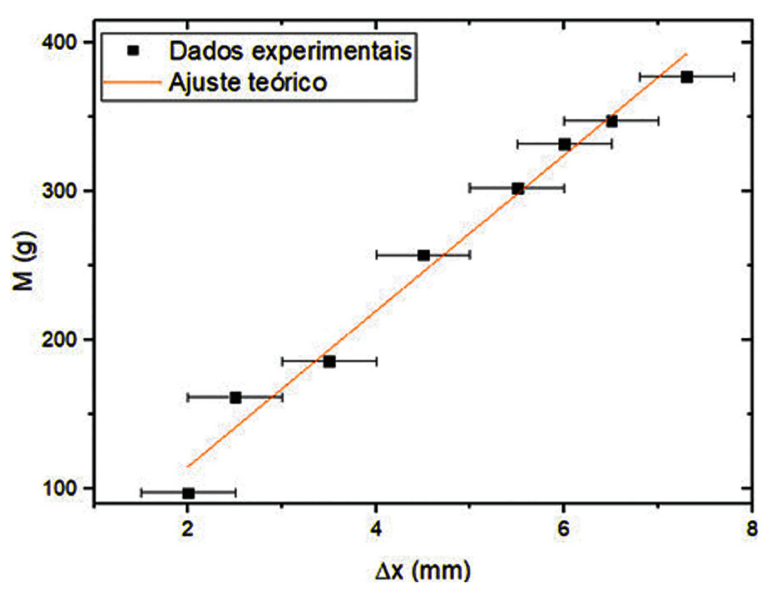

Figura 3: Gráfico dos dados experimentais submetidos à equação (4), cujas barras de erros se referem à incerteza de $0,5 \mathrm{~mm}$ da régua utilizada.

da marca na régua, é possível formar uma função linear com as duas variáveis, tal como na equação (4):

$$
m=\frac{k}{g} \Delta x
$$

Submetendo os dados experimentais à equação (4), foi obtido o gráfico na Figura 3 onde as barras de erros se referem à incerteza de $0,5 \mathrm{~mm}$ da régua utilizada. $\mathrm{O}$ coeficiente angular da reta ajustada apresentou o seguinte valor:

$$
\frac{k}{g}=(52 \pm 5) \mathrm{g} / \mathrm{mm}
$$

Aproximando o valor da aceleração gravitacional para $g=9,8 \mathrm{~m} / \mathrm{s}^{2}$ [10], foi obtido o valor $k=(509 \pm 5) \mathrm{N} / \mathrm{m}$ para a constante elástica da mola utilizada.

A calibração da pressão exercida pela caneta sobre uma camada de folhas de papel sulfite A4 $75 \mathrm{~g} / \mathrm{m}^{2}$, foi calculada em função da deformação causada à folha durante o processo de escrita. Por questões didáticas, foram consideradas apenas as deformações normais causadas pela força aplicada e admitiu-se que a deformação no papel causada pela ponta esférica da caneta corresponde exatamente à geometria da deformação. Em outras palavras, as tensões devidas à contração do papel e do atrito, paralelas ao plano do papel, são consideradas desprezíveis. Abaixo descrevemos o procedimento.

\subsection{Desenvolvimento e utilização do suporte para caneta}

Após a calibração da mola, foi desenvolvido um suporte para caneta responsável pela regulagem da força aplicada pela caneta à superfície em que ela estivesse em contato. Para isso, foi utilizado um tubo de PVC, um tubo de alumínio menor, a mola calibrada e um tambor de micrômetro. A caneta é mantida presa ao tubo de alumínio, que é inserido ao tubo de PVC abaixo da 


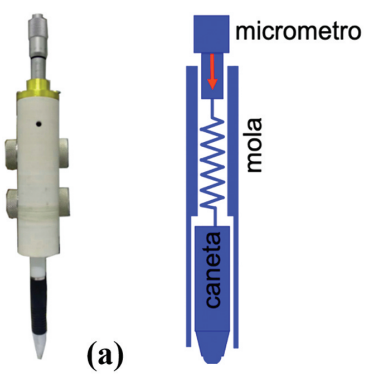

(b)

Figura 4: (a) Foto do dispositivo desenvolvido para aplicação de força conhecida no papel para calibração da pressão (b) esquema interno do dispositivo. O micrômetro aplica um deslocamento na mola que exerce uma força conhecida sobre a caneta.

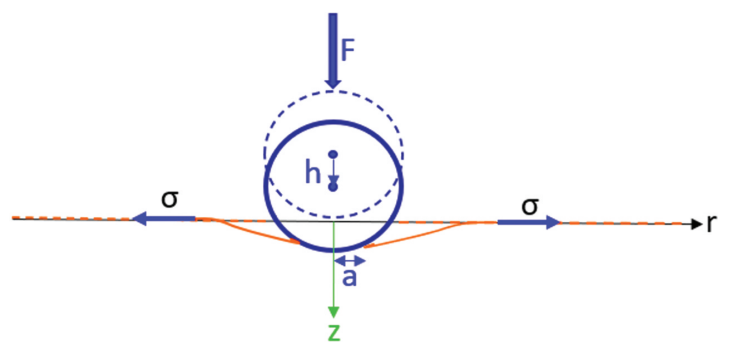

Figura 5: Representação das tensões transversais causadas à folha sulfite, identificadas por $\sigma$.

mola calibrada. Na parte superior externa do tudo de PVC foi encaixado o tambor de micrômetro, de forma que ele estivesse em contato com a mola. Na Figura 4 encontram-se as estruturas interna e externa do suporte desenvolvido.

Uma vez que o conjunto suporte e caneta esteja em contato com uma superfície, à medida que o tambor do micrômetro foi deslocado, a mola era comprimida, exercendo força elástica sobre a caneta. A caneta, por sua vez, causa uma deformação à superfície, cujo formato é o mesmo da ponta visível dela, ou seja, o de uma calota esférica; além disso, ela exerce uma força sobre cada ponto da área deformada, que pode ser dividida em componentes horizontal e vertical (Figura 5). Para dois pontos da área que estejam na mesma altura, as componentes horizontais das forças aplicadas em cada um têm as mesmas intensidades e sentidos opostos, assim, ao calcularmos a força resultante aplicada na região - e desprezando-se os efeitos das componentes horizontais -, a resultante tem direção vertical e mesma intensidade da força elástica que a mola aplica sobre a caneta. Dessa forma, a utilização do suporte tornou possível a regulagem da força aplicada pela caneta à superfície em contato.

Para a obtenção de amostras para a calibração do papel sulfite, o suporte foi acoplado a um translador linear que o movia horizontalmente, de forma que a caneta permanecesse na vertical sobre 5 folhas de sulfite A4 $75 \mathrm{~g} / \mathrm{m}^{2}$ sobrepostas (Figura 6). Foram realizados

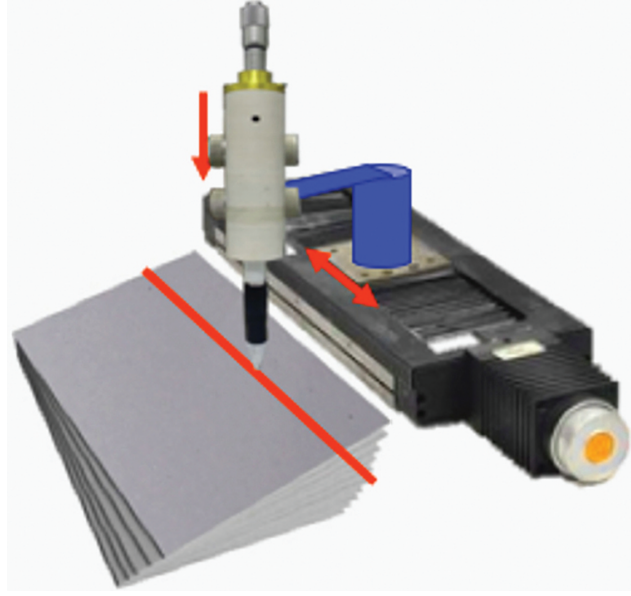

Figura 6: Dispositivo de deslocamento automático da caneta, com velocidade constante.

vários traçados paralelos pelo deslocamento lateral da caneta sobre o papel, a cada traço o micrometro foi deslocado de $0,5 \mathrm{~mm}$ aumentando a força aplicada pela mola, e, portanto, aumentando a pressão que a caneta exerceu sobre o papel. Este processo foi repetido 25 vezes, quando o micrometro chegou ao deslocamento máximo (máxima pressão aplicada). Em todos os casos foi calculada a intensidade da força que a caneta exercia à folha superior devido à compressão da mola.

\subsection{Método de calibração da folha sulfite}

Cada traçado obtido foi submetido ao tomógrafo óptico OCP930RS - Thorlabs, Inc, na qual foram obtidas imagens sequenciais de seções transversais de cada um, que juntas, formam uma reprodução tridimensional do risco. A técnica OCT é capaz de produzir imagens tomográficas a partir de um meio espalhador e é baseada no interferômetro de Michelson, o qual faz uso da propriedade de coerência temporal da fonte luminosa. Por utilizar uma fonte de luz de grande largura de banda, ou baixa coerência temporal, o interferômetro de Michelson apresenta franjas de interferência somente para diferenças de caminho óptico entre os braços do interferômetro menores que o comprimento de coerência da fonte de luz utilizada. A Figura 7 apresenta o diagrama básico de um sistema de OCT, neste caso por utilizar um espectrômetro para detectar a interferência ele é chamado de FDOCT, "Fourier Domain OCT", neste caso as franjas espectrais são captadas por um espectrômetro e a imagem é reconstruída no computador $[11$.

O sistema utiliza uma LED superluminescente com comprimento de onda centrado em $\lambda=930 \mathrm{~nm}$, com largura de banda de $\Delta \lambda=100 \mathrm{~nm}$, gerando imagens de $2000 \times 512$ pixeis (largura $\mathrm{x}$ profundidade), com varredura de $6,0 \mathrm{~mm} \times 1,5 \mathrm{~mm}$, com resolução espacial lateral de $10 \mu \mathrm{m}$ e em profundidade de $6,0 \mu \mathrm{m}$ no ar, e é capaz de gerar até 8 imagens por segundo. 


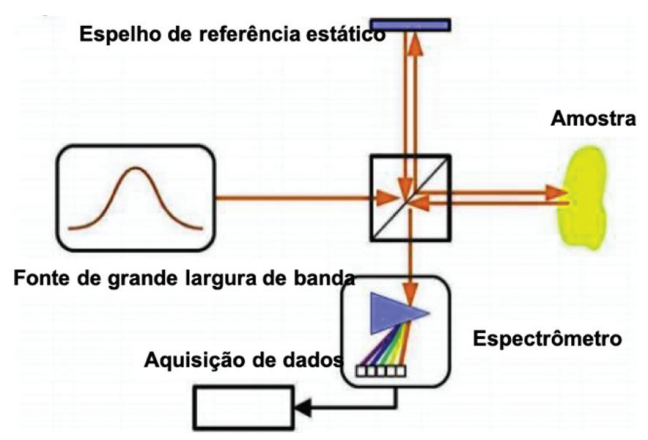

Figura 7: Diagrama de OCT no domínio de Fourier. A luz espalhada da amostra e a luz refletida do espelho de referência são combinadas para gerar franjas de interferência espectral no espectrômetro.

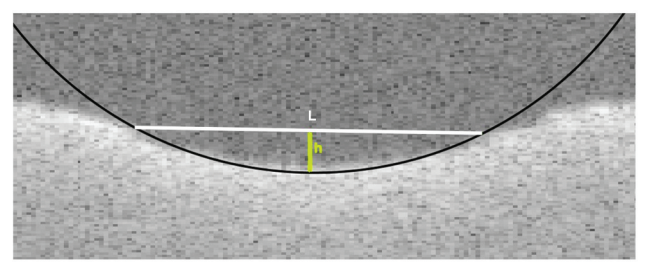

Figura 8: Imagem de seção transversal de uma das amostras coletadas, na qual foi ajustada uma circunferência de diâmetro de $1 \mathrm{~mm}$ (em preto, sendo $1 \mathrm{~mm}$ o valor suposto inicialmente para o diâmetro da esfera na ponta da caneta) e, a partir dela, foram medidas a largura $\mathrm{L}$ (em branco) e a profundidade $\mathrm{h}$ (em amarelo) da deformação.

\subsection{Aplicação: Detecção de falsificação em assinaturas manuscritas}

Para uma aplicação prática, comparou-se as deformações causadas pela escrita em diferentes tipos diferentes de papel por cinco voluntários que tentaram reproduzir uma dada assinatura original. As diferentes deformações atribuídas a cada escritor caracterizam a individualização da escrita. Em cada um dos 25 conjuntos de imagens obtidos, foram selecionadas 10 figuras para serem analisadas por meio do software Image ${ }^{\circledR}$. A análise consistiu em medir a profundidade da deformação causada pela caneta e, com isso, determinar a área deformada e a medida do raio da esfera da caneta por meio de um algoritmo especialmente desenvolvido para essa finalidade. Na Figura 8 encontra-se uma das imagens coletadas com as medições de sua largura $L$ e profundidade $h$ em mícron.Apesardeserpossívelmediralarguratotal

da deformação por meio do mesmo software, ela não foi realizada, pois parte dela não é causada apenas pela caneta, mas pelas tensões transversais que esta causa ao papel. Ao pressionarmos uma caneta à folha de papel, parte dela se deforma, mesmo não estando em contato com a ferramenta, tal como na Figura 8. Isso se deve ao fato de o papel ser um material elástico. Considerando que é extremamente difícil diferenciar a região deformada pela caneta daquela deformada pela

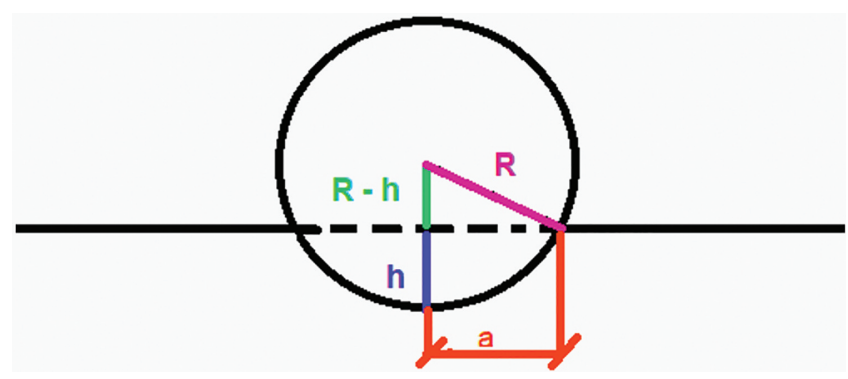

Figura 9: Relação entre as medidas de $R, h$ e a.

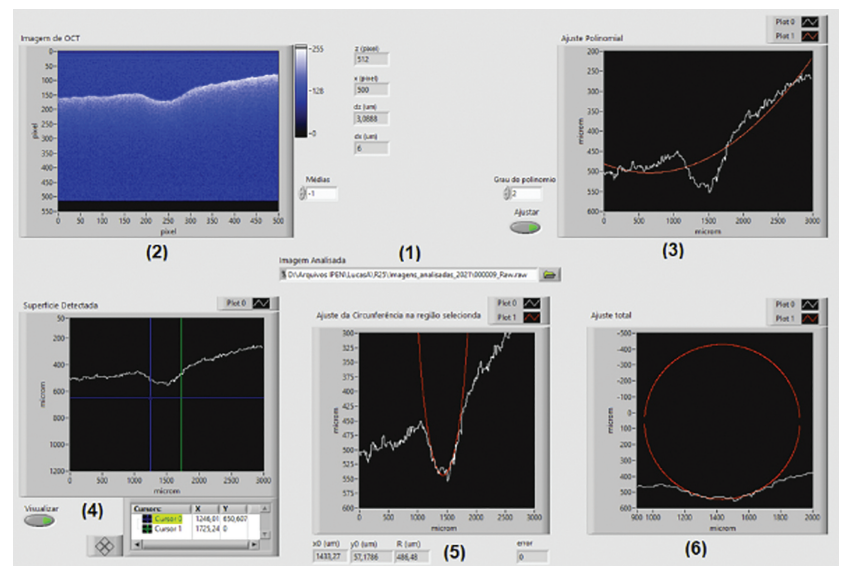

Figura 10: Interface do algoritmo desenvolvido, já com os ajustes de polinômio e circunferência realizados em uma das imagens de seção transversal de um dos traçados tomados no papel sulfite $75 \mathrm{~g} / \mathrm{m}^{2}$.

tensão transversal, não foi realizada a medida da largura total, pois utilizá-la causaria erro à medição da pressão exercida pela caneta sobre a folha.

Lembrando que a pressão é a intensidade da força aplicada por unidade de área em uma superfície [12], e que a intensidade da força aplicada pela caneta sobre a folha sulfite foi obtida anteriormente, ainda era necessário calcular os valores de área deformada. Como a caneta utilizada em todos os casos tem a ponta esférica, ao ser pressionada contra o papel, ela causa uma deformação na forma de uma calota esférica. Observando a Figura 9 onde $R$ representa o raio da caneta, $h$, a profundidade da deformação e $L$, a largura, temos a relação expressa pela equação (5), onde $a=\frac{L}{2}$. A equação (6) representa a área de uma calota esférica.

$$
\begin{gathered}
R^{2}=(R-h)^{2}+a^{2} \\
A=2 \pi R h
\end{gathered}
$$

O raio da caneta foi determinado pela utilização de um software desenvolvido que ajusta uma circunferência à cada imagem de seção transversal do traço e devolve os valores de $R$ (Figura 10). Estes valores, em conjunto com as medidas da profundidade da deformação $h$, foram submetidos à equação (6), para que fosse realizado o 


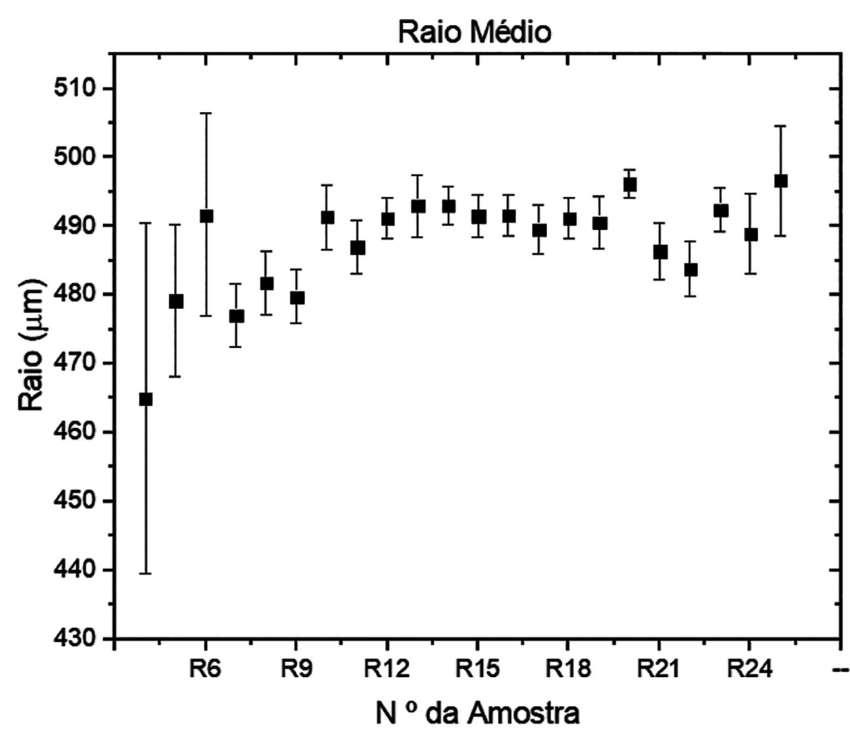

Figura 11: Valores médios de raio, com os respectivos desvios padrão, obtidos em cada amostra pelo algoritmo de ajuste.

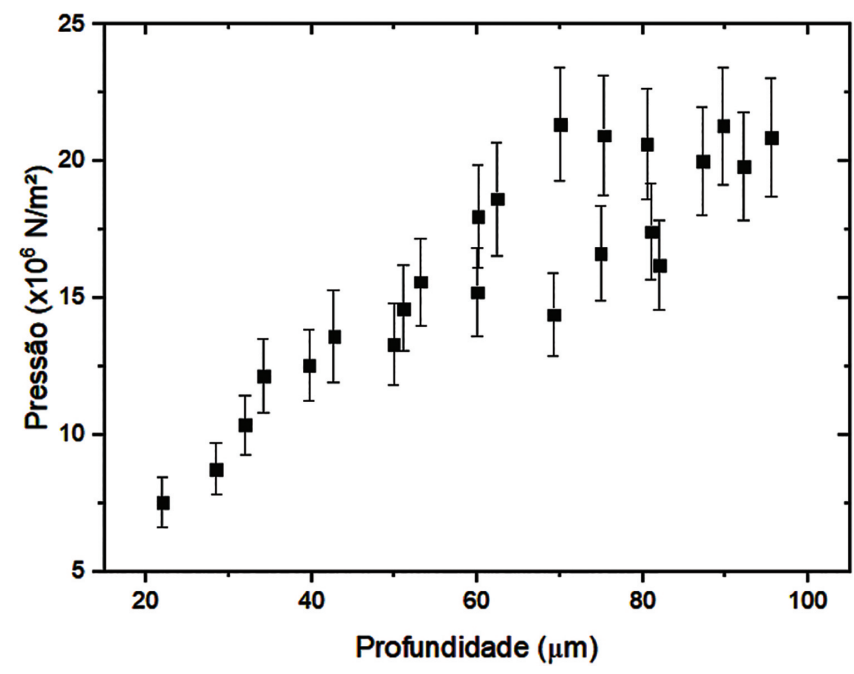

Figura 12: Valores obtidos de pressão em função da profundidade.

cálculo da área deformada pela caneta. Além disso, foram realizados os gráficos do raio $R$ em função do número da amostra (Figura 11), para a verificação do quanto o raio variou quando determinado pelo algoritmo, e a pressão $P$ em função de medida da profundidade da deformação $h$, para a calibração da pressão aplicada ao papel sulfite (Figura 12).

\subsection{Algoritmo para obtenção do raio da caneta esférica}

$\mathrm{O}$ algoritmo em questão foi desenvolvido no ambiente de programação Labview ${ }^{\circledR}$ (National Instruments), que utiliza a linguagem de programação em diagrama de blocos e fluxo de dados. Ele consiste em ajustar a função de uma circunferência à uma imagem de seção transversal obtida pelo tomógrafo óptico, devolvendo os valores de raio e centro do ajuste em unidades $\mu \mathrm{m}$. Lembrando que apesar das imagens terem as medidas em pixel, o algoritmo as converte em $\mu m$ por meio da leitura do arquivo stream.srm, que é gerado pelo tomógrafo em conjunto com a imagem. Este arquivo contém os parâmetros de aquisição das imagens pelo tomógrafo. $\mathrm{Na}$ Figura 10 encontra-se a interface do algoritmo, já com os ajustes realizados.

O funcionamento do software consiste em:

(1) O usuário escolhe a imagem para análise;

(2) Programa lê o arquivo stream presente na pasta da imagem e a reproduz graficamente;

(3) Realiza a detecção das bordas da imagem, convertendo a superfície detectada em um vetor.

(4) Realiza um ajuste polinomial à deformação da imagem;

(5) Usuário seleciona a região para o ajuste da circunferência;

(6) Reproduz o ajuste da circunferência na região selecionada e devolve os valores de raio e centro dela;

(7) Reproduz toda a Circunferência ajustada

Tendo os valores médios de raio para cada amostra, o cálculo da área deformada não necessita da largura da deformação, uma vez que ele pode ser realizado com a utilização da equação (6). O gráfico resultante do valor médio de raio para cada amostra, com o respectivo desvio padrão, encontra-se na Figura 11

O gráfico mostra que os valores médios de raio da esfera variaram entre $465 \mu m$ e $500 \mu m$. Tomando como valor final do raio a média dos 21 valores presentes no gráfico, e tomando como incerteza o desvio padrão dessa nova média, temos como resultado o valor $R=$ $488 \pm 2 \mu m$ apresentando maior concordância entre os valores a partir da amostra 10. Considerando que os raios das pontas de canetas esféricas variam entre $350 \mu \mathrm{m}$ e $500 \mu \mathrm{m}$ [13], a utilização do algoritmo apresentou ótimo resultado em relação aos valores originais.

Em relação à calibração da pressão sobre o papel sulfite, percebe-se que a pressão apresentou comportamento linear em relação à profundidade até os $60 \mu \mathrm{m}$, onde houve divergência de dados (Figura 12). Ainda assim, foi ajustada uma reta à parte linear do gráfico para a calibração da pressão em função da profundidade (Figura 13). O resultado obtido foi de uma taxa de pressão por profundidade de $\left((2,46 \pm 0,24) \times 10^{6} \mathrm{~N} \mathrm{~m}^{-2}\right.$ $\left.\mu \mathrm{m}^{-1}\right)$.

\subsection{Reconhecimento de Deformação e Pressão de Punho}

\subsubsection{Pressão de punho no sulfite $75 \mathrm{~g} / \mathrm{m}^{2}$}

Com a calibração do papel sulfite $\mathrm{A} 475 \mathrm{~g} / \mathrm{m}^{2}$ realizada, foi possível demonstrar experimentalmente a pressão de 


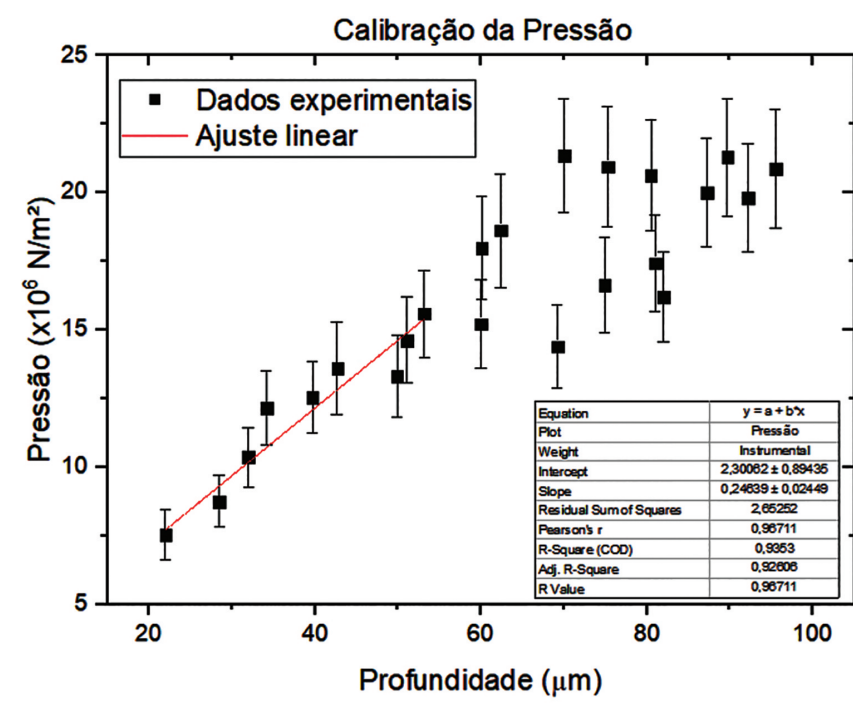

Figura 13: Ajuste linear ao gráfico de dados da pressão em função da profundidade da deformação.

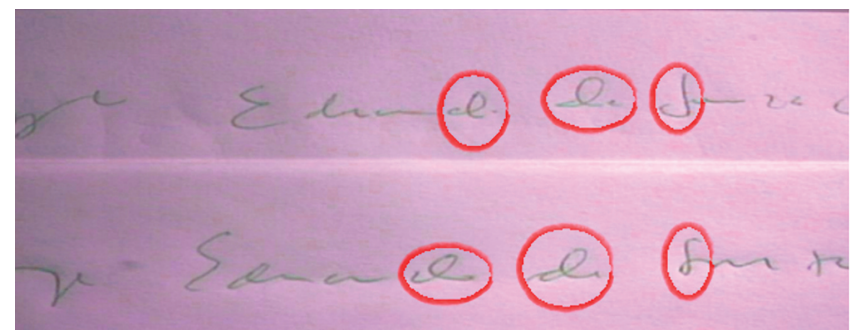

Figura 14: Assinaturas coletadas, onde a superior é a autêntica, e a segunda é a falsa.

punho. Para isso, dois voluntários escreveram a mesma assinatura com a utilização da mesma caneta esférica. O primeiro voluntário a escrever foi definido como Autor, enquanto que o segundo, que tentou copiar a assinatura, foi definido como Falsário. Em cada uma delas, foram selecionadas três letras para a análise por tomografia por coerência óptica. Na Figura 14 encontram-se cada uma das assinaturas, com as letras submetidas a análise destacadas.

As imagens obtidas foram separadas em seis grupos, representados por "NL", onde N representa a posição da imagem na sequência (como por exemplo, na figura anterior, a letra "S" é a terceira letra na sequência das destacadas); e "L", é a letra analisada. Além disso, em cada uma delas foram observadas duas deformações causadas pela escrita, que foram definidas como DD (deformação direita) e DE (deformação esquerda). Veja nas Figura 15 e Figura 16 as imagens transversais das amostras 3SA e 3SF, onde estão destacadas as deformações mencionadas, também perceba que na autêntica há maiores profundidades do que na falsária. Cada uma das medições de deformação obtidas foi submetida à calibração da pressão no sulfite. Os gráficos resultantes de pressão por número da figura encontram-se nas Figura 17] a Figura 22.

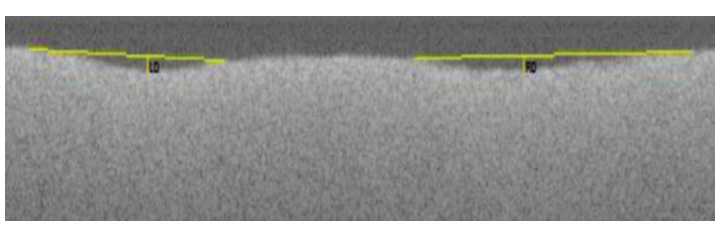

Figura 15: Amostra 3SA, com as deformações destacadas.

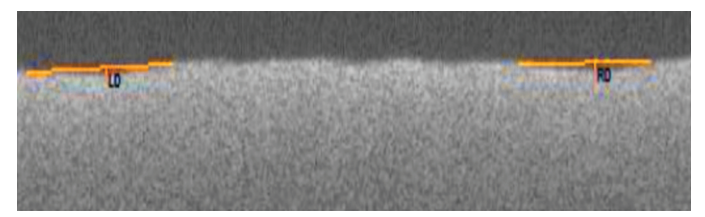

Figura 16: Amostra 3SF, com as deformações destacadas.

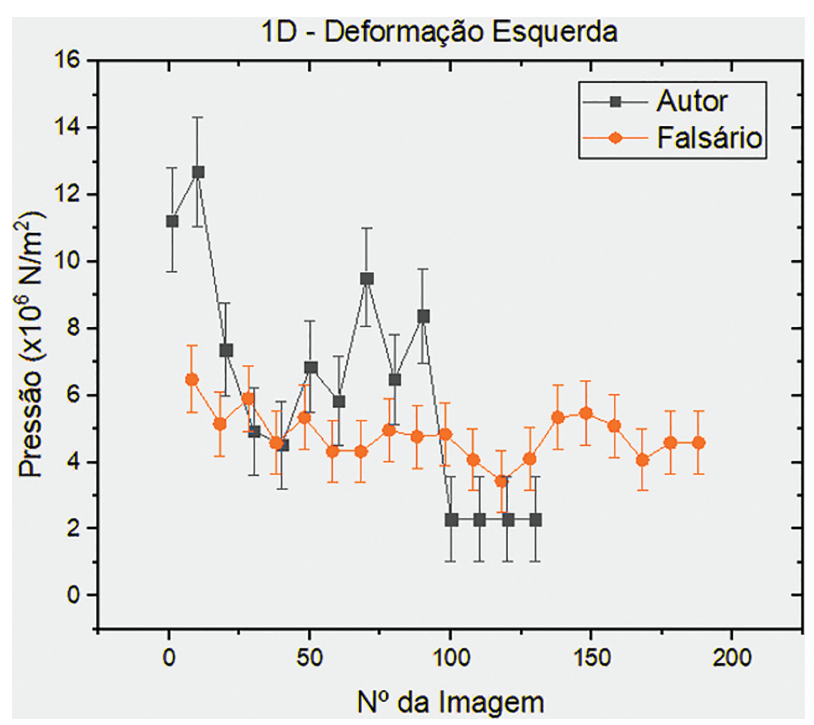

Figura 17: Comparação entre os valores de pressão de cada voluntário na deformação esquerda da amostra 1D.

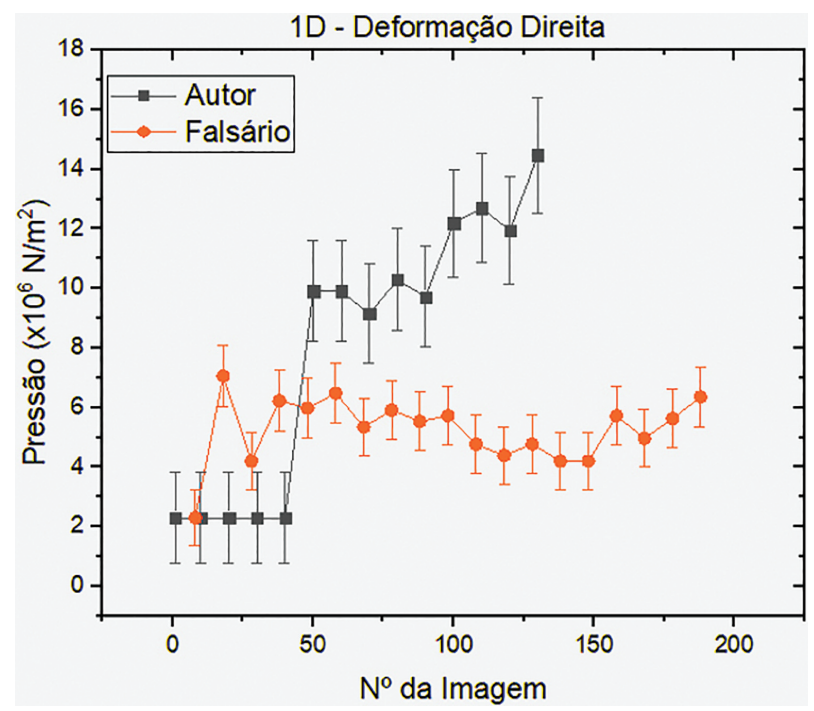

Figura 18: Comparação entre os valores de pressão de cada voluntário na deformação direita da amostra 1D. 


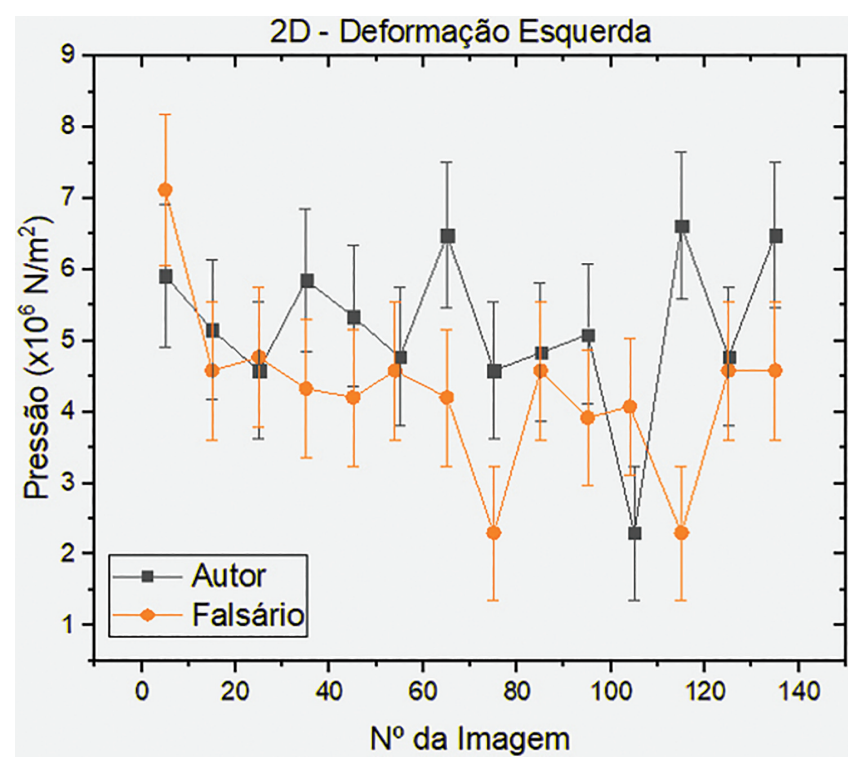

Figura 19: Comparação entre os valores de pressão de cada voluntário na deformação esquerda da amostra 2D.

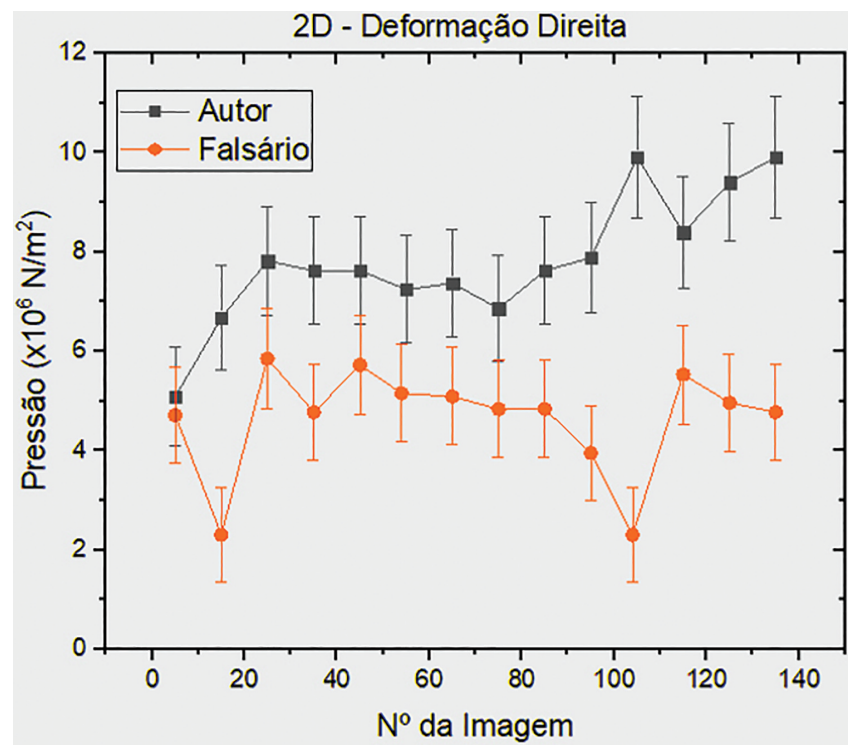

Figura 20: Comparação entre os valores de pressão de cada voluntário na deformação direita da amostra 2D.

A única análise que apresentou compatibilidade entre as assinaturas, devido às incertezas, foi a 2D - esquerda, (Figura 19). Em todas as outras, a pressão exercida pelo autor foi muito superior à do falsário, demonstrando a impossibilidade de duas pessoas apresentarem a mesma pressão de punho.

\subsection{Deformação de punho em vários tipos de papel}

Para a comparação entre as profundidades causadas por pessoas diferentes, foi realizada uma atividade análoga à anterior, onde houve a cooperação de 5 voluntários

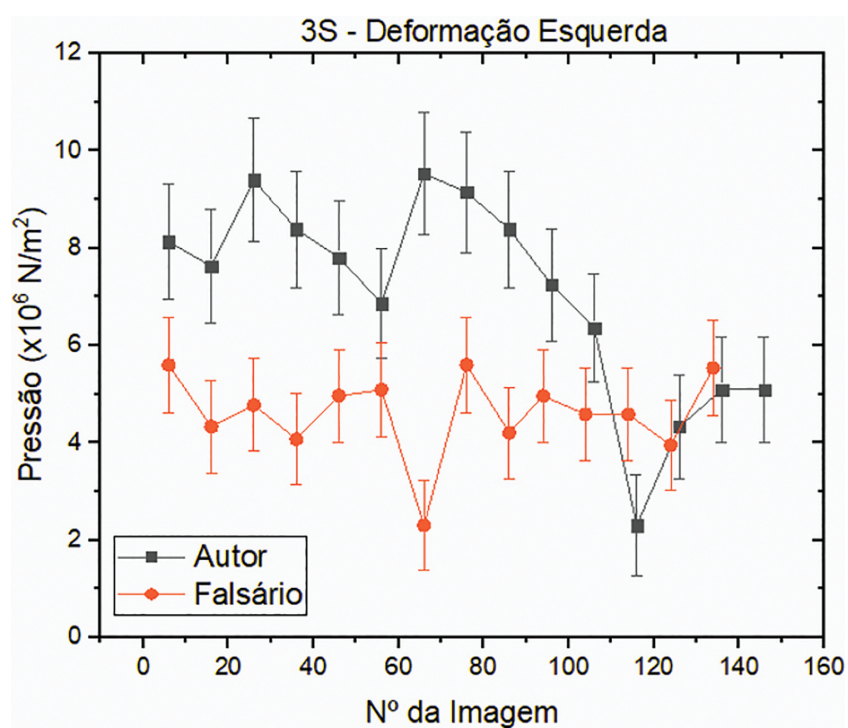

Figura 21: Comparação entre os valores de pressão de cada voluntário na deformação esquerda da amostra 3S.

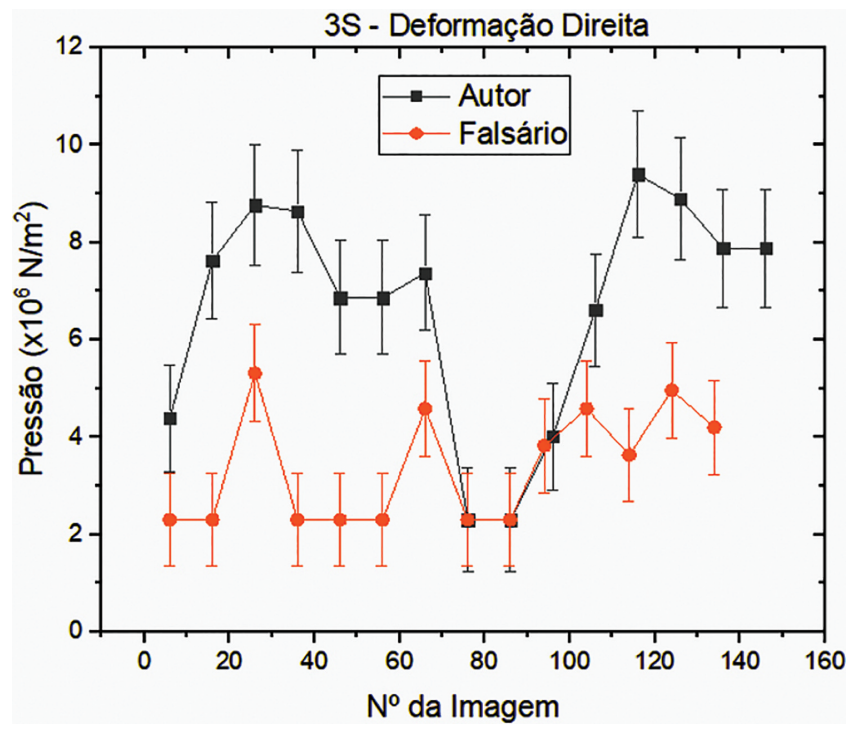

Figura 22: Comparação entre os valores de pressão de cada voluntário na deformação direita da amostra $3 S$.

que tentaram escrever a mesma assinatura em 4 tipos diferentes de papel, Verge $120 \mathrm{~g} / \mathrm{m}^{2}$ e Verge $80 \mathrm{~g} / \mathrm{m}^{2}$, sulfite $90 \mathrm{~g} / \mathrm{m}^{2}$ e Color Plus $80 \mathrm{~g} / \mathrm{m}^{2}$. Novamente, o primeiro voluntário a escrever a assinatura foi definido como Autor (A), enquanto que os outros quatro, que tentaram copiar a mesma assinatura, foram definidos como falsários, sendo identificados pela letra inicial (FA, FC, FN e FM). Em todas as assinaturas coletadas, foram selecionadas as mesmas duas sílabas, sendo que em cada uma delas, foram selecionadas 3 regiões para a análise óptica, definidas como regiões de interesse (ou ROI Region of Interest). Na Figura 23 estão destacadas as ROI escolhidas nas sílabas "do" e "de" da assinatura original. 


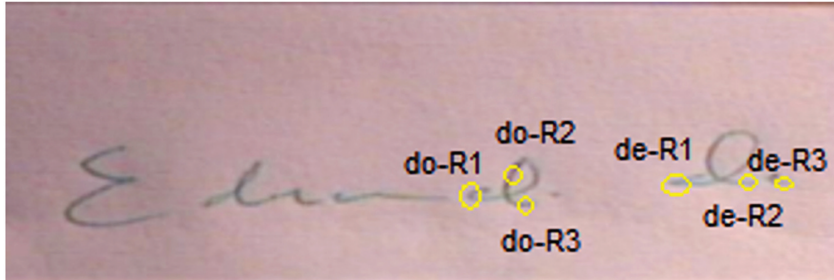

Figura 23: Assinatura original, com as regiões de interesse marcadas nas sílabas "do" e "de".

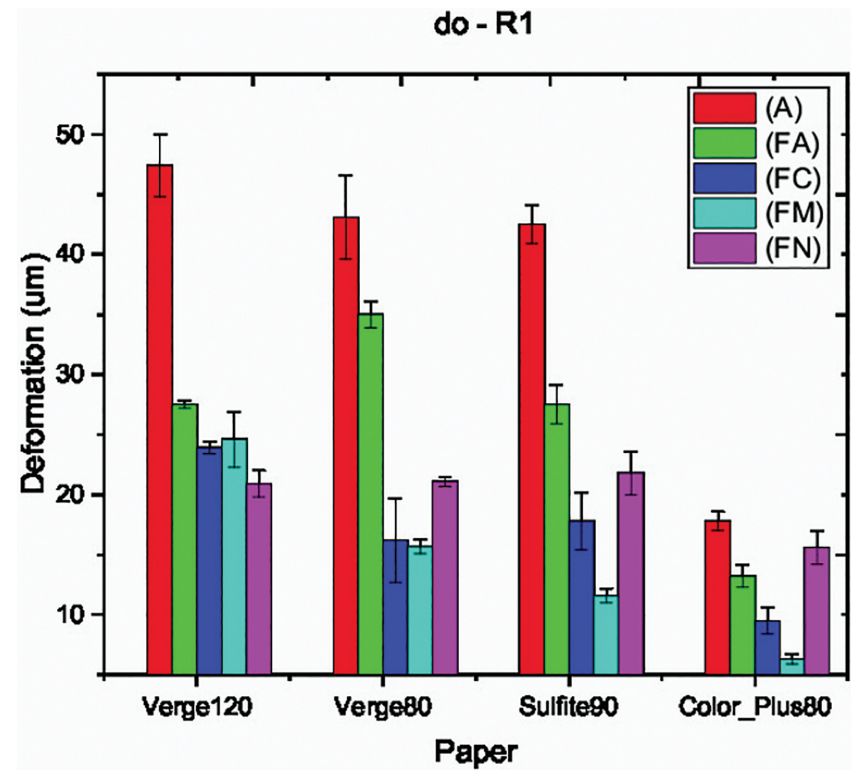

Figura 24: Gráfico de comparação da deformação média causada por cada voluntário em cada tipo de papel na região de interesse 1 da sílaba "do".

Como resultado, foram gerados os gráficos de barra de profundidade média por tipo de papel para cada autor, de cada região de interesse, que podem ser observados nas Figuras 24 a 29

Com a análise dos gráficos, temos como resultado em cada tipo de papel: Nos papéis Verge $120 \mathrm{~g} / \mathrm{m}^{2}$ e Verge $80 \mathrm{~g} / \mathrm{m}^{2}$, apenas o voluntário FA apresentou deformações médias com valores próximos aos do autor. Ainda assim, isso não ocorreu em todas as regiões de interesse, como pode ser visto em "do - R1", onde a deformação causada por FA é muito inferior à do autor, em ambos os tipos de papel citados. Isso também ocorre nos gráficos de "do - R2" e "de - R2" especificamente para o papel Verge $120 \mathrm{~g} / \mathrm{m}^{2}$. Além disso, também não ocorre compatibilidade no gráfico "de - R3", onde a deformação média de FA é muito superior à do autor. Dessa forma, é possível diferenciar a autoria nesses dois tipos de papel, uma vez que não houve compatibilidade em todas as regiões de interesse.

Para o papel sulfite $90 \mathrm{~g} / \mathrm{m}^{2}$, percebe-se que todos os falsários tiveram deformações médias muito menores do que as do autor em todas as regiões de interesse. Mesmo

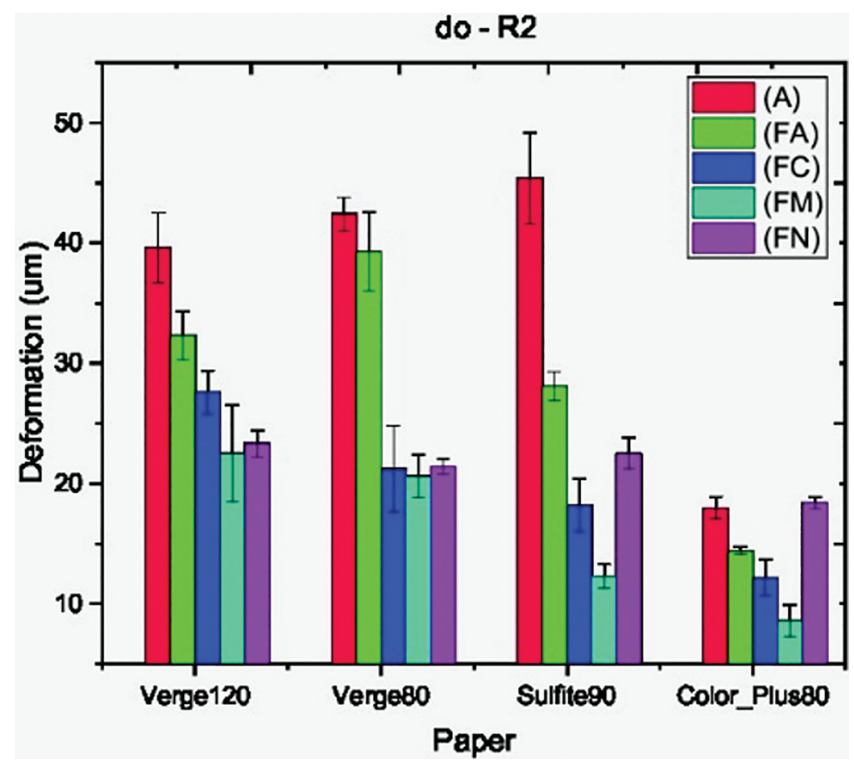

Figura 25: Gráfico de comparação da deformação média causada por cada voluntário em cada tipo de papel na região de interesse 2 da sílaba "do".

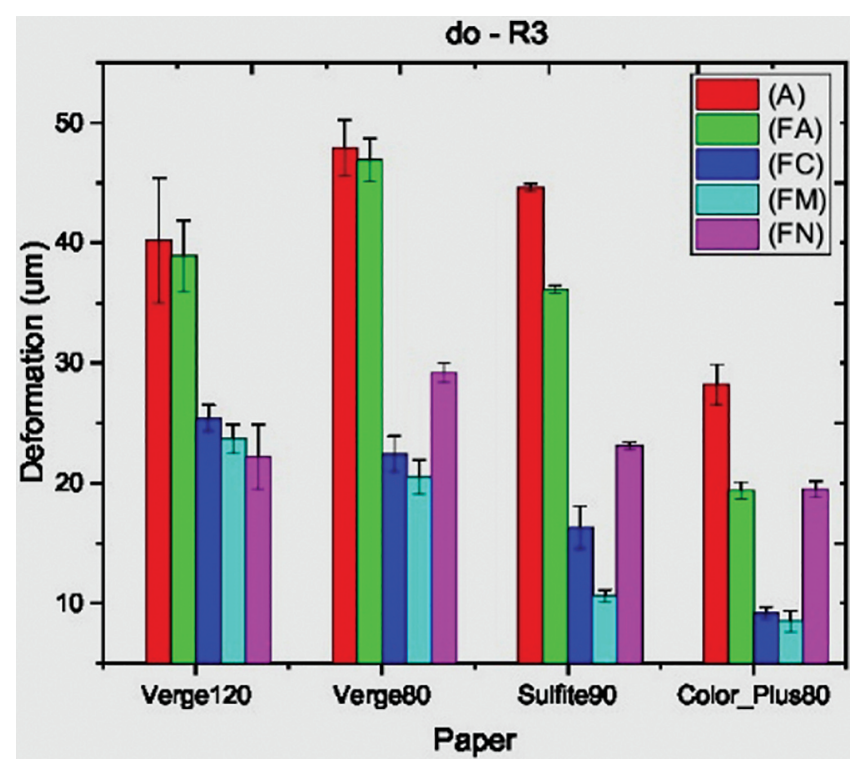

Figura 26: Gráfico de comparação da deformação média causada por cada voluntário em cada tipo de papel na região de interesse 3 da sílaba "do".

entre eles, não houve valores próximos, o que possibilita identificar qual falsário escreveu cada assinatura.

No caso do papel Color Plus $80 \mathrm{~g} / \mathrm{m}^{2}$, todos os voluntários apresentaram deformações médias de intensidades muito menores do que nos outros tipos de papel, dificultando a identificação da autoria da amostra, uma vez que os falsários FA e FN tiveram valores médios muito próximos aos do autor, havendo compatibilidade entre eles devido ao intervalo de incerteza de cada um. Isso se deve à rigidez deste tipo de papel, que impede 
de-R1

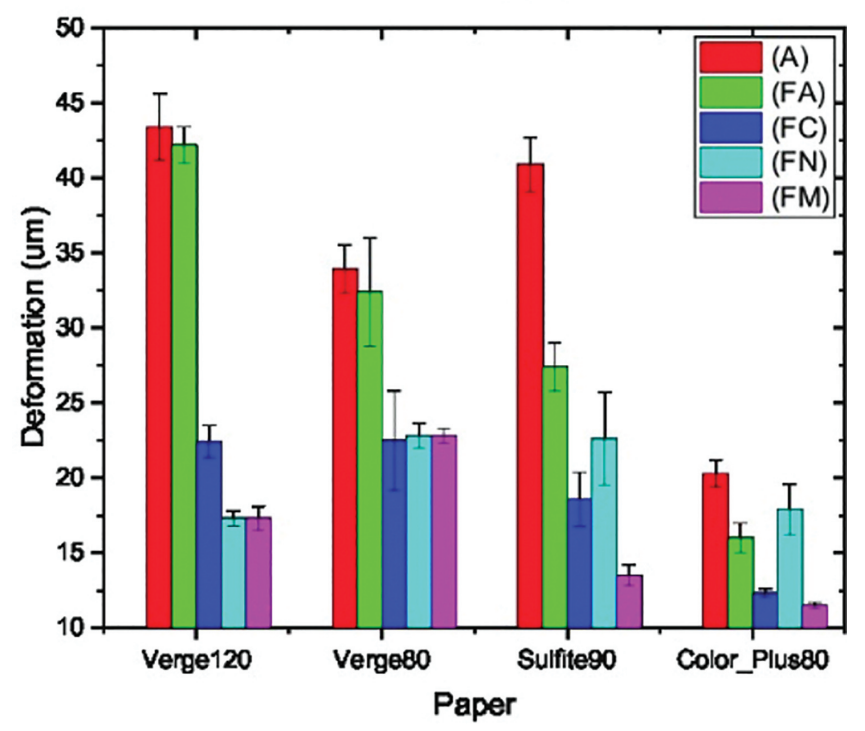

Figura 27: Gráfico de comparação da deformação média causada por cada voluntário em cada tipo de papel na região de interesse 1 da sílaba "de".

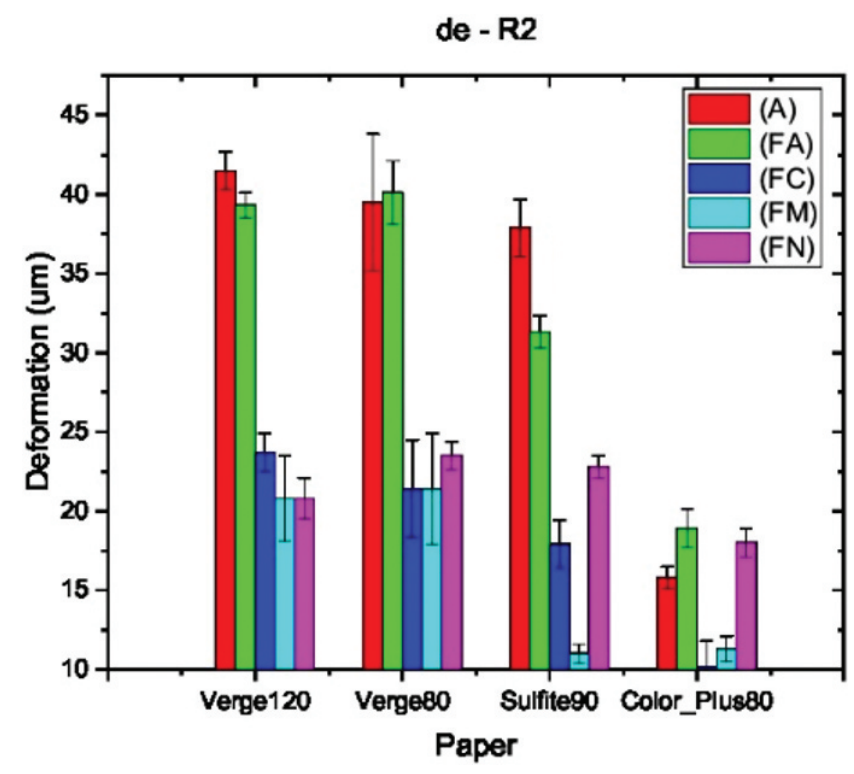

Figura 28: Gráfico de comparação da deformação média causada por cada voluntário em cada tipo de papel na região de interesse 2 da sílaba "de".

que haja deformações profundas quando comparado aos outros tipos de papel analisados.

\section{Discussão}

A rigidez de uma superfície de papel depende de diversas variáveis, como o módulo de Young, a densidade, a espessura e ainda da rede fibrosa que compõe a estrutura do papel. Uma das constantes mais difíceis de avaliar no papel é o Coeficiente de Poisson (CP) [12, em

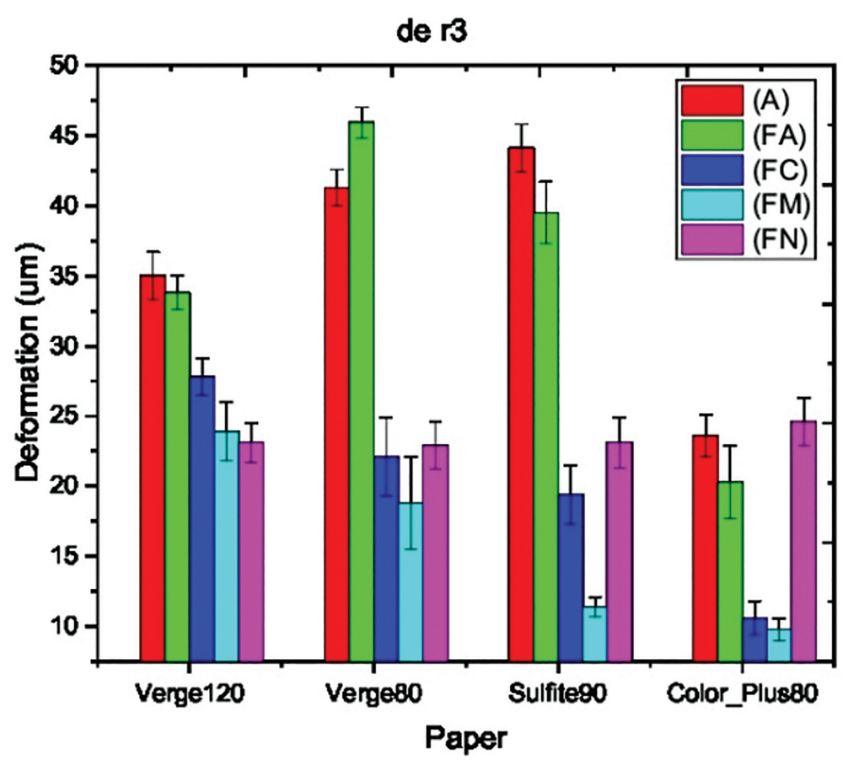

Figura 29: Gráfico de comparação da deformação média causada por cada voluntário em cada tipo de papel na região de interesse 3 da sílaba "de".

virtude das propriedades ortotrópicas deste material. Entretanto, partindo da definição do CP como sendo a relação entre a deformação transversal e a longitudinal sofrida pelo material sob ação de uma carga, avaliamos o $\mathrm{CP}$ aparente a partir dos dados obtidos no experimento:

$$
\nu=\frac{e_{x}}{e_{z}}=-\frac{e_{y}}{e_{z}}
$$

Com a determinação do valor de $\nu$ define-se o Módulo de Young efetivo $E^{*}$ pela expressão:

$$
\frac{1}{E^{*}}=\frac{\left(1-\nu_{1}^{2}\right)}{E_{1}}+\frac{\left(1-\nu_{2}^{2}\right)}{E_{2}}
$$

onde $E_{i}$ é o Módulo de Young medido experimentalmente $\left(E_{\text {exp }}\right)$ para os corpos pressionado (1) e carga (2); $\nu_{i}$ são os respectivos coeficientes de Poisson.

No caso em estudo, podemos considerar, sem perda de generalidade, $E_{2} \rightarrow \infty$. $E_{1}-$ módulo de Young do papel suporte - pode ser medido diretamente da relação entre a carga e a deformação relativa mostrada na Figura 13

Em se tratando da superfície de uma folha de papel, o coeficiente de Poisson é uma das constantes de mais difícil determinação [14. No caso de uma folha fina de papel, entretanto, é possível medir diretamente essas relações e avaliar empiricamente $\nu$. Em virtude de sua estrutura fibrosa, é difícil notar a orientação das fibras do papel (Figura 30). Por outro lado, as medidas realizadas em nossa experiência apontaram para um valor do coeficiente de Poisson entre 0,1 e 0,3, portanto, dentro da faixa de valores para $\nu$ indicada na literatura [12].

A metodologia da obtenção do coeficiente de Poisson consistiu em medir a profundidade total $(\mathrm{H})$ e a largura total (L) da deformação sobre as amostras obtidas anteriormente para o cálculo do raio da esfera da ponta 


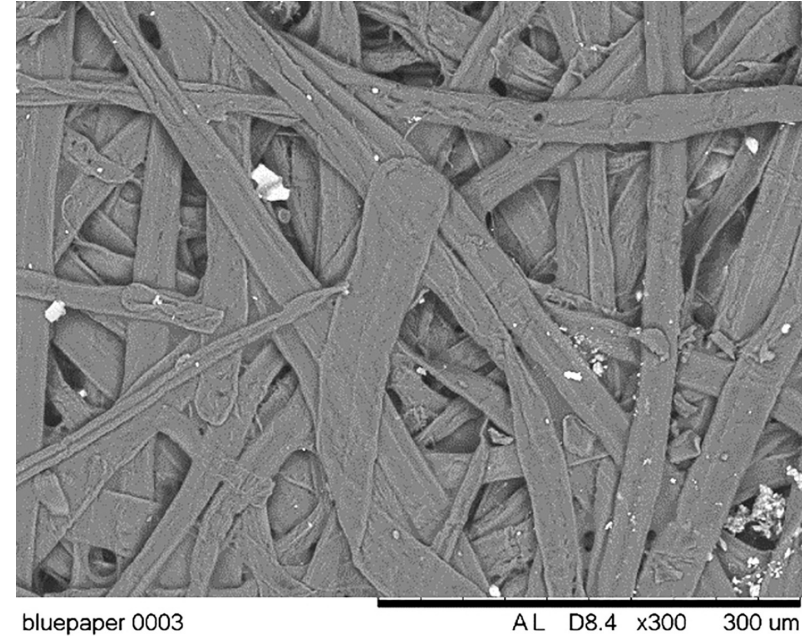

Figura 30: Micrografia eletrônica de varredura de uma folha de papel (adaptado de [14]).

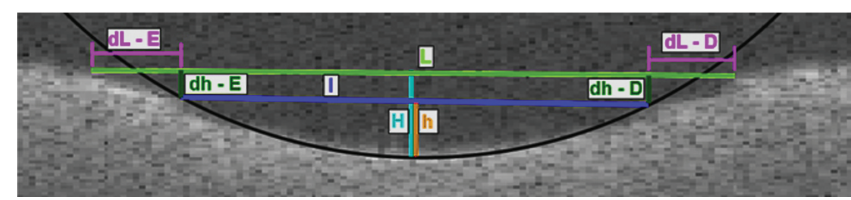

Figura 31: Medições realizadas em cada amostra para a obtenção do coeficiente de Poisson $\nu$.

Tabela 1: Coeficiente de Poisson calculado para cada amostra.

\begin{tabular}{|c|c|c|c|c|c|}
\hline \multicolumn{6}{|c|}{ Amostra $n^{\circ} 15$} \\
\hline Figura & DL-E & DL-D & DL & $\mathrm{H}$ & $\mathrm{v}=\mathrm{H} / \mathrm{DL}$ \\
\hline 11 & 97,47 & 121,93 & 219,4 & 76,75 & 0,349818 \\
\hline 40 & 167,82 & 59,67 & 227,49 & 56,15 & 0,246824 \\
\hline 66 & 71,69 & 110,36 & 182,05 & 51,13 & 0,280857 \\
\hline 105 & 78,18 & 96,03 & 174,21 & 64,59 & 0,370759 \\
\hline 132 & 148,03 & 134,98 & 283,01 & 90,56 & 0,319989 \\
\hline 162 & 109,81 & 121,14 & 230,95 & 72,14 & 0,312362 \\
\hline 212 & 197,24 & 127,65 & 324,89 & 71,76 & 0,220875 \\
\hline 254 & 116,66 & 52,86 & 169,52 & 70,51 & 0,415939 \\
\hline 271 & 130,35 & 129,84 & 260,19 & 64,6 & 0,24828 \\
\hline 286 & 96,8 & 158,3 & 255,1 & 64,08 & 0,251196 \\
\hline & & Média & & & 0,30169 \\
\hline \multicolumn{5}{|c|}{ vio Padrão } & 0,019991 \\
\hline
\end{tabular}

da caneta utilizada. Em posse de tais dados, foram medidas as diferenças de largura $(\mathrm{dL}-\mathrm{X}$, onde $\mathrm{X}$ pode ser $\mathrm{D}$ - direita ou $\mathrm{E}$ - esquerda) e de altura $(\mathrm{dh}-\mathrm{X})$. $\mathrm{Na}$ Figura 31, encontram-se as medições realizadas em cada amostra. O coeficiente de Poisson de cada amostra foi a calculado pela razão entre H e DL:

$$
\nu=\frac{H}{D L}, \operatorname{com} D L=D L-E+D L-D
$$

Os resultados obtidos estão expostos na Tabela 1 .
A partir da equação (7) e o valor médio de $\nu$, acima obtido, podemos avaliar o valor de Módulo de Young efetivo $E^{*}$ através da expressão:

$$
E^{*}=\frac{E_{e x p}}{\left(1-\nu^{2}\right)}
$$

\section{Conclusões}

Foi desenvolvida uma metodologia que possibilitou a aplicação de uma força conhecida à uma caneta durante o processo de escrita. Esse desenvolvimento permitiu a calibração de uma mola, que foi utilizada na criação de um suporte para caneta, responsável pela regulagem da força aplicada pela caneta sobre o papel. O suporte possibilitou a obtenção de amostras de deformações causadas por uma caneta ao papel sulfite com diferentes profundidades. As medidas dessas profundidades em conjunto com o valor do raio da caneta utilizada, obtido por meio do software desenvolvido especialmente para essa finalidade, e das intensidades da força que foi aplicada à caneta tornou possível a calibração da pressão em função da profundidade da deformação causada por ela ao papel sulfite.

Demostramos que é possível utilizar essa metodologia para avaliar a pressão de punho durante o processo de escrita manual, e que cada pessoa apresenta uma pressão de punho própria, sendo praticamente impossível ser copiada integralmente por outra pessoa.

Realizamos também o estudo em função do tipo de substrato, onde cinco voluntários que tentaram copiar a mesma assinatura em quatro tipos diferentes de papel, o auxílio da técnica de tomografia por coerência óptica, demonstrou que é possível diferenciar a autoria de uma assinatura também pela profundidade da deformação no papel [15].

Foi possível também determinar o coeficiente de Poisson do papel sulfite $75 \mathrm{~g} / \mathrm{m}^{2}$, e determinar o Módulo de Young efetivo.

\section{Agradecimentos}

Os autores agradecem as agências de fomento: FAPESP processo $\mathrm{n}^{\circ}$ 2019/20112-4 e 2013/20502-0, e CNPq processo $n^{\circ} 449440 / 2014-1$ pela infraestrutura de laboratório e ao CNPq processo $\mathrm{n}^{\circ} 129737 / 2021-6$ pela bolsa de iniciação científica do aluno Lucas A. S Ribeiro.

\section{Referências}

[1] V. Popov, E. Willert e M. Hess, Handbook of Contact Mechanics (Springer, Berlin, 2019).

[2] E.S. Pellat, Le Role de La Graphologie Dans L'Expertise en Ecritures (1908) (Kessinger Publishing, Paris, 2010).

[3] L.B. Mendes, Documentoscopia (Millennium Editora, Campinas, 2003).

[4] D. Huang, E.A. Swanson, C.P. Lin, J.S. Schuman, W.G. Stinson, W. Chang, M.R. Hee, T. Flotte, K. Gregory, C.A. Puliafito et al., Science, 254, 1178 (1991). 
[5] A.Z. Freitas, M.M. Amaral e M.P. Raele, em: Laser Pulse Phenomena and Applications, editado por F. J. Duarte (I-Tech Education and Publishing, Austria 2010), p. 409.

[6] W. Drexlere e J.G. Fujimoto, Optical Coherence Tomography: Technology and Applications (Springer, Berlin, 2008).

[7] A.M. Zysk, F.T. Nguyen, A.L. Oldenburg, D.L. Marks e S.A. Boppart, J. Biomed. Opt. 12, 051403-1 (2007).

[8] W.S. Rasband, U.S. ImageJ, National Institutes of Health, Bethesda, Maryland, USA, disponível em: https:// imagej.nih.gov/ij/, 1997-2018, acessado em02/01/2022.

[9] A. Jones, Experimental Investigation of the in-plane elastic moduli of paper. Tese de Doutorado, University of Colorado, Colorado (1967).

[10] C-Y Hui, T Liu, T Salez, E. Raphael e A. Jagota, Proc. R. Soc. A 471, 20140727 (2015).

[11] M.P. Raele, Desenvolvimento de um sistema de tomografia por coerência óptica no domínio de Fourier sensivel á polarização e sua utilização na determinação das matrizes de Mueller. Dissertação Mestrado, Universidade de São Paulo, São Paulo (2009).

[12] W. Szewczyk, Fiber and Textiles in Eastern Europe 16, 117 (2008).

[13] Ballpoint pen (2020), disponível em: https://en.wiktion ary.org/wiki/ballpoint_pen, acessado em 28/09/2021.

[14] S. Lavrikov, K.M. Singh, Nordic Pulp and Paper Research Journal 27, 256 (2012).

[15] O. Negrini Neto, J.E.S. Sarkis, A.N. Siqueira, L.A.S Ribeiro e A. Z. Freitas, ANALYST 146, 1973 (2021). 